\title{
EFICIÊNCIA ENERGÉTICA COM BASE NOS CRITÉRIOS PROCEL: ESTUDO DE CASO EM EDIFÍCIO PÚBLICO
}

\author{
A. L. FERRADOR FILHO ${ }^{1, *}$, A. O. AGUIAR ${ }^{2}$, C. T. KNIESS ${ }^{3}$ \\ 1,2,3 Universidade Nove de Julho - UNINOVE \\ alexandre@aguiar.eng.br*
}

Submetido 18/04/2018 - Aceito 16/10/2018

DOI: $10.15628 /$ holos.2018.7216

\section{RESUMO}

O investimento em eficiência energética de edifícios tem sido um assunto prioritário, incluindo nos órgãos públicos. O tema é importante pelo potencial de aliar economia de energia com redução de custos, quanto por dar exemplo de boas práticas para a sociedade. Esta pesquisa buscou identificar oportunidades de melhorias em eficiência energética em um edifício público do Tribunal de Justiça de São Paulo. Os dados do estudo de caso foram coletados em entrevistas não estruturadas e visitas técnicas, e por exame de documentação relacionada. Para avaliação da eficiência energética foi usado o método prescritivo da etiquetagem PROCEL-
Edifica. A envoltória foi caracterizada com a etiqueta $D$, a iluminação a etiqueta $\mathrm{C}$ e o condicionamento de ar a etiqueta B. A classificação geral do prédio foi etiqueta $C$. Algumas das potenciais melhorias identificadas foram: mudança de lâmpadas fluorescentes para LED, alteração no circuito de iluminação de salas, uso de filmes polarizados nos vidros, melhoria no sombreamento vertical e horizontal das fachadas da torre pela utilização de elementos que diminuam a incidência direta da luz solar, como brises. O tempo de retorno de investimento para algumas melhorias foi calculado, indicando possíveis ações prioritárias.

PALAVRAS-CHAVE: Eficiência energética de edifícios, Selos de eficiência energética, Retrofit, Construções sustentáveis, Certificações

\section{ENERGY EFFICIENCY BASED ON PROCEL CRITERIA: CASE STUDY IN A PUBLIC BUILDING}

\begin{abstract}
Investment in energy efficiency of buildings has been a priority issue, including in public administration. The theme is important because of the potential to combine energy savings with cost reduction, and to provide examples of good practices for society. This research aimed at identifying improvements opportunities in energy efficiency in a public building of the São Paulo's Justice Court. The case's data was collected in unstructured interviews and technical visits, and by examining related documentation. The data were analyzed by the label PROCEL-Edifica's prescriptive
\end{abstract}

method. The envelope was characterized label $D$, the lighting label $C$ and the air conditioning with label $B$. The building as a whole achieved label $C$. Some of the potential improvements identified were: change of fluorescent lamps to LEDs, changes in the lighting circuit in office rooms, use of polarized films in the windows glasses, improvement in the vertical and horizontal shading of the tower façades by the use of elements that decrease the sunlight direct incidence, such as brises. Examples of investment return time analysis were calculated, indicating potential priority in actions.

KEYWORDS: Building energy efficiency, Energy efficiency labels, Retrofit, Sustainable constructions, Certifications. 


\section{INTRODUÇÃO}

O investimento em eficiência energética tem tido prioridade em inúmeros países, e em especial são importantes os investimentos em eficiência na ponta do consumo (Girod, Stucki, \& Woerter, 2017). O Brasil vem implementando políticas relacionadas a eficiência energética (Altoé et al., 2017). Entre as iniciativas podem ser citadas a rotulagem de produtos energeticamente eficientes, como: o Programa Brasileiro de Etiquetagem PBE-INMETRO; o Programa Nacional de Uso Racional do Uso de Derivados de Petróleo e Gás Natural - CONPET; e o PROCEL - Programa Nacional de Conservação de Energia Elétrica - PROCEL (Eletrobras), que inclui a rotulagem de aparelhos eletrodomésticos e edificações, entre outros; ações voltadas a tecnologias específicas como o uso de motores elétricos de alta eficiência e o planejamento da eliminação de lâmpadas incandescentes do mercado, e os planos de longo prazo como o Plano Nacional de Energia (PNE) 2030 e o Plano Nacional de Eficiência Energética (PNEF). O PNEF deriva do PNE e consolida vários dos instrumentos existentes.

As edificações são importantes consumidoras de recursos como energia e água e também geradoras de resíduos. Em torno de $40 \%$ da energia elétrica consumida na maioria dos países é derivada da utilização em edificações (Chen, Cook \& Crandall, 2013). Já construções causam cerca de um terço de toda a emissão de $\mathrm{CO}_{2}$ (Memon, 2014). Vários autores indicam a existência de um enorme potencial de economia a ser estudado, tratado e otimizado em relação à eficiência energética de edifícios (Lowe, 2000; Juan, Gao, \& Wang, 2010; Zheng, Jing, Huang, Zhang, \& Gao, 2009). A renovação que busca a eficiência energética do conjunto de edifícios existentes é considerada fator chave para a redução de emissões de $\mathrm{CO}_{2}$. Segundo Lowe (2000) e McCormick et al. (2016), praticar ações para melhorar a eficiência energética é um caminho importante para atingir esses objetivos.

O setor público controla grandes orçamentos e tem poder de compra de uma vasta gama de produtos e serviços (Biderman, Macedo, Monzoni, \& Mazon, 2006). É também responsável por cerca de $8,2 \%$ do consumo de energia elétrica no Brasil (Brasil, 2016). Uma parcela das edificações em uso pertence ou é alugada ao poder público. Torna-se importante passo no sentido a sustentabilidade que este poder atue na melhoria da eficiência energética e da redução da emissão de $\mathrm{CO}_{2}$ de suas propriedades. A partir de 2014, passa a existir no Brasil uma determinação do Ministério do Planejamento, Orçamento e Gestão, para que edifícios novos, a serem construídos ou alugados, e reformas acima de $500 \mathrm{~m} 2$, controlados pela administração federal, sejam nível "A" no selo do Instituto Nacional de Metrologia, Qualidade e Tecnologia (INMETRO) e Programa Brasileiro de Conservação de Energia (PROCEL), voltado a edificações, o PROCEL-Edifica, como forma de induzir e incentivar edifícios energeticamente eficientes (Brasil, 2014).

Nesse sentido, o Conselho Nacional de Justiça (CNJ), por meio da resolução 201, de 03 de Março de 2015, determinou a implantação de núcleos socioambientais e de Planos de Logística Sustentável (PLS), como instrumentos para melhorar o desempenho socioambiental do sistema judiciário (CNJ, 2015). Atendendo a esta determinação, o Tribunal de Justiça do Estado de São Paulo (TJ/SP), elaborou um PLS, em que um dos destaques foi o objetivo de reduzir o consumo de energia. 
O presente trabalho discute os resultados de um projeto de pesquisa resultante do convênio entre uma universidade e o TJ/SP, com vistas a estudar a classificação atual de um dos edifícios do TJ/SP tendo por base os critérios do PROCEL para identificar possibilidades de melhoria de eficiência energética. Nessa linha, pretende-se responder a seguinte questão de pesquisa: como utilizar os critérios do PROCEL-Edifica/PBE-Edifica como base para definição de ações para melhoria da eficiência energética de edifícios do TJ/SP?

O trabalho buscou contribuir, do ponto de vista prático, para que o TJ/SP possa priorizar ações de eficiência energética, e do ponto de vista teórico-científico, discutindo a consistência entre os métodos estabelecidos pelo PROCEL e o potencial de replicação do método em outros prédios da instituição.

O artigo é composto por esta introdução; uma seção de referencial teórico abordando o ciclo de vida das construções e a eficiência energética em edifícios; a descrição dos métodos utilizados no estudo de caso incluindo as fontes de informação e métodos de análise; a descrição do caso estudado e os resultados da análise de eficiência energética do edifício e a classificação obtida de acordo com os critérios Procel; a discussão dos resultados incluindo as propostas para melhoria de eficiência e as suas consequências na classificação energética do edifício; e termina com uma seção de conclusões.

\section{FUNDAMENTAÇÃO TEÓRICA}

Os dois temas-chave da fundamentação teórica são o ciclo de vida das construções, que aborda os principais impactos e a fase de operação como mais importante para o consumo de energia, embora seja influenciada pelo projeto; e os aspectos técnicos da eficiência energética em edificações.

\subsection{Ciclo de vida das construções}

O ciclo de vida das construções pode ser dividido basicamente em três fases distintas: construção, incluindo todo o processo de concepção, projeto, além de extração, fabricação, transporte e uso das matérias-primas e insumos; operação, que é o uso efetivo da edificação pelos seus ocupantes, seja ela residencial, comercial, pública, educacional e outras. O ciclo de vida do edifício pode terminar na demolição, com a desconstrução total do edifício, ou na requalificação, caso em que se realiza uma extensa reforma para um novo uso (Huberman \& Pearlmutter, 2008). O ciclo de vida das construções é ilustrado pela Figura 1. 


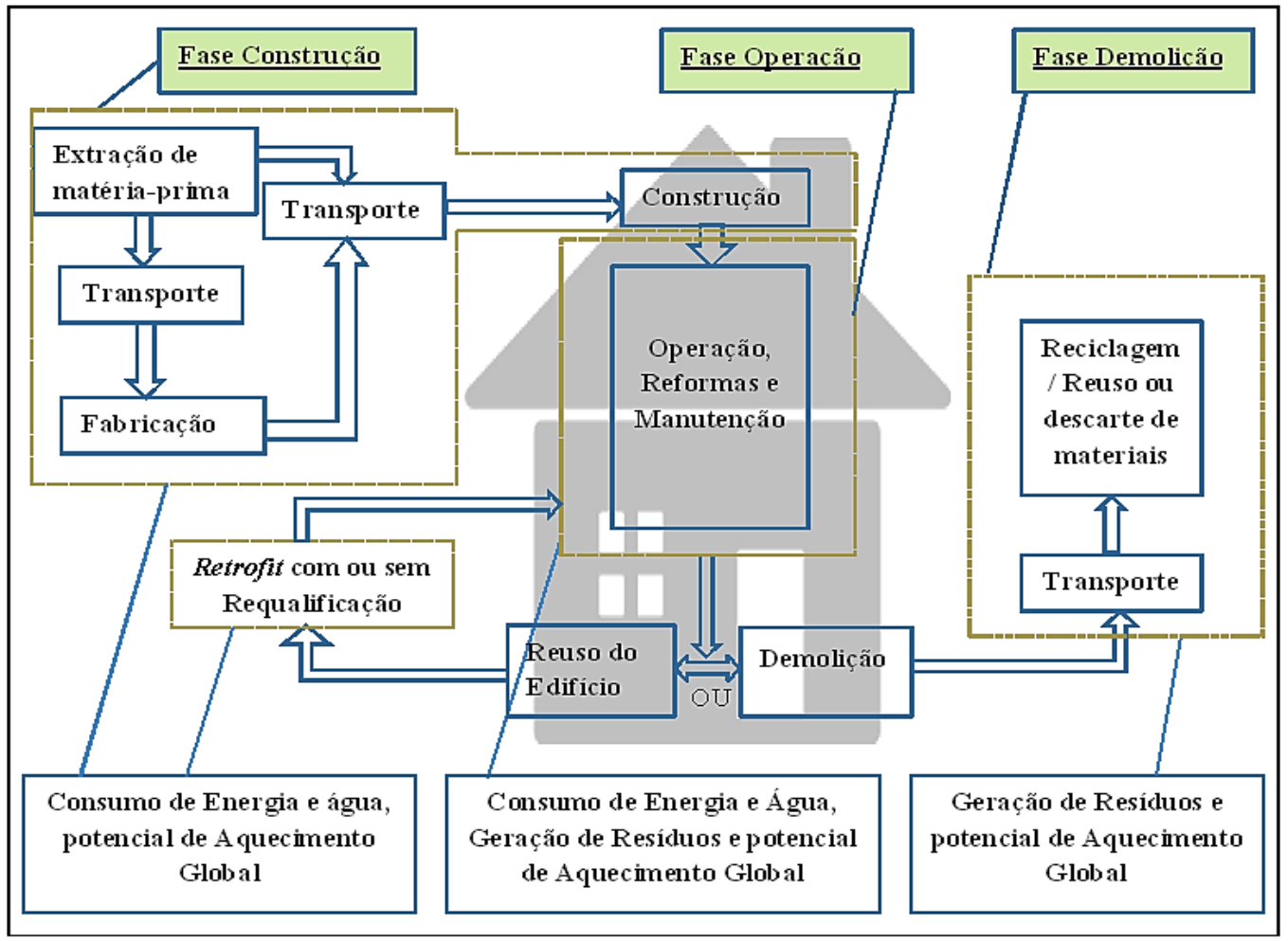

Figura 1: O ciclo de vida das edificações

As construções têm uma grande parcela na agressão ao meio ambiente em termos globais. Representam, segundo autores como (Tianzhen Hong, Chou, \& Bong, 2000); (Chen, Cook, \& Crandall, 2013) (Praznik, Butala, \& Senegačnik, 2014), uma das maiores consumidoras de recursos naturais, água e energia elétrica, além de ser uma das maiores geradoras de resíduos e de emissões de gases de efeito estufa. O Relatório do Programme des Nations Unies pour l'environnement (UNEP, 2011) aponta na mesma direção, colocando as edificações como consumidoras de alto impacto e potencialmente causadoras do aquecimento global. Isto acontece durante todas as fases de seu ciclo de vida (Sedláková, Vilčeková, \& Burdová, 2015).

A operação é o período mais longo do ciclo de vida e em que existe o maior impacto ambiental relativo a consumo de água e energia elétrica (Ortiz-Rodríguez, Castells, \& Sonnemann, 2012). O ar condicionado e o aquecimento (nos países frios) são os principais consumidores de energia nessa fase (Liu, Shukla, \& Zhang, 2014).

Decisões tomadas durante a concepção e projeto do edifício, envolvendo temas como localização, orientação, especificação de materiais, equipamentos e nível de automação da operação são determinantes no consumo energético ao longo da vida útil. Decisões envolvendo esses aspectos devem permear os projetos de engenharia e arquitetura de modo a proporcionar conforto e eficiência energética (Degani \& Cardoso, 2002). No entanto, as edificações existentes nem sempre foram construídas levando em consideração os parâmetros de sustentabilidade e, conforme mostra o ciclo de vida, é na sua fase de operação em que ocorrem os maiores gastos energéticos e emissões de gases de efeito estufa. Isto demonstra a importância de se considerar reformas voltadas à melhoria de parâmetros de eficiência energética. Custos relativamente baixos para estas reformas podem trazer efeitos satisfatórios a médio e longo prazo para as construções, tornando-as mais sustentáveis (Ma, Cooper, Daly, \& Ledo, 2012). 


\subsection{Eficiência Energética em edificações}

Entre os aspectos importantes a serem considerados no projeto das edificações estão as características de sua envoltória, os materiais de construção e as facilidades de automação das instalações.

A conjunção de escolhas favoráveis na envoltória e dos materiais de construção permite aplicar o conceito de construção passiva, que é um tipo de construção voltada a proporcionar conforto aos seus ocupantes com o mínimo uso de energia (Schnieders \& Hermelink, 2006). Construções já existentes e que não foram desenvolvidas dentro do conceito de construção "passiva" necessitam de reformas para que possam ter melhor desempenho em eficiência energética, conforto térmico e outros, conforme mostram (Moran, Blight, Natarajan, \& Shea, 2014).

A Figura 2 mostra alguns exemplos de medidas de eficiência energética (MEE) e materiais a serem usados na melhoria do desempenho energético de edificações.

\begin{tabular}{|c|c|}
\hline MEE / Materiais & Vantagem \\
\hline $\begin{array}{l}\text { Vidros especiais com menor transmitância } \\
\text { térmica e melhor absorção de UV }\end{array}$ & $\begin{array}{l}\text { Reduzir o calor e os raios UV associados a luz natural (ARCOweb, } \\
\text { 2005) (M. A. M. A. Ferreira, 2009) (Lamberts et al., 2005) }\end{array}$ \\
\hline $\begin{array}{l}\text { Filme polarizado para janelas sem ou com } \\
\text { controle por automação. }\end{array}$ & Controle da luz natural com economia de iluminação e aquecimento. \\
\hline $\begin{array}{l}\text { Materiais com alta absorção de calor para } \\
\text { paredes externas (materiais de mudança } \\
\text { de fase) }\end{array}$ & $\begin{array}{l}\text { Redução da necessidade de aquecimento e refrigeração artificiais } \\
\text { (Memon, 2014). }\end{array}$ \\
\hline Tinta branca para pintura telhado & Reduz absorção de radiação solar \\
\hline $\begin{array}{l}\text { Utilização de cobertura "verde" no } \\
\text { telhado ou laje }\end{array}$ & $\begin{array}{l}\text { Melhorar arrefecimento térmico e prevenir efeito "ilhas de calor" } \\
\text { (Ferreira, 2009) }\end{array}$ \\
\hline Melhorar isolamento das janelas & $\begin{array}{l}\text { Melhor aproveitamento do condicionamento artificial (Cheung, Mui, } \\
\text { \& Wong, 2015) }\end{array}$ \\
\hline $\begin{array}{l}\text { Aplicar material para melhor isolamento } \\
\text { das paredes e teto (poliestireno, por } \\
\text { exemplo) }\end{array}$ & $\begin{array}{l}\text { Melhor aproveitamento do aquecimento (climas frios) e refrigeração } \\
\text { artificiais. } \\
\text { (Krarti, 2015) } \\
\text { Reduzir perdas por condução } \\
\text { (M. A. M. A. Ferreira, 2009) }\end{array}$ \\
\hline $\begin{array}{l}\text { Ajustar a abertura das fachadas (mais ou } \\
\text { menos envidraçadas) }\end{array}$ & $\begin{array}{l}\text { Melhorar aproveitamento luz natural } \\
\text { (Cheung et al., 2015) } \\
\text { (Ferreira, 2009) }\end{array}$ \\
\hline Procurar melhorar ventilação natural & $\begin{array}{l}\text { Reduzir necessidade de resfriamento artificial e melhorar o conforto } \\
\text { térmico } \\
\text { (Ferreira, 2009) }\end{array}$ \\
\hline $\begin{array}{l}\text { Substituir lâmpadas convencionais por } \\
\text { LEDs }\end{array}$ & $\begin{array}{l}\text { Eficiência energética (menor consumo) } \\
\text { (Krarti, 2015) (Ferreira, 2014) }\end{array}$ \\
\hline Uso de luz solar "encanada" & $\begin{array}{l}\text { Aproveitamento luz natural (redução uso iluminação artificial) } \\
\text { (Jenkins \& Muneer, 2003) }\end{array}$ \\
\hline Uso de brises & $\begin{array}{l}\text { Protege contra o excesso de exposição a radiação solar (Venâncio \& } \\
\text { Pedrini, 2008), (Lamberts et al., 2005) }\end{array}$ \\
\hline $\begin{array}{l}\text { Substituir condicionadores de ar antigos } \\
\text { por novos de maior desempenho }\end{array}$ & $\begin{array}{l}\text { Reduzir o consumo de energia mantendo o mesmo conforto térmico } \\
\text { (Cheung et al., 2015) }\end{array}$ \\
\hline
\end{tabular}

Figura 2: Medidas de eficiência energética e materiais 
Uma terceira forma de obter ganhos de eficiência é a utilização de tecnologias de automação. Alguns exemplos de tecnologias de automação para edificações disponíveis são mostrados na Figura 3.

\begin{tabular}{|l|l|}
\hline \multicolumn{1}{|c|}{ Tecnologia } & \multicolumn{1}{c|}{ Oportunidade de melhoria } \\
\hline Automação da iluminação & $\begin{array}{l}\text { Eliminação ou redução de desperdícios por controle mais efetivo, independente do } \\
\text { usuário ou facilitado para ele. Possibilidades de criação de "cenas" (power-off geral, } \\
\text { por exemplo)(Li, 2013) }\end{array}$ \\
\hline $\begin{array}{l}\text { Automação do Ar- } \\
\text { condicionado }\end{array}$ & $\begin{array}{l}\text { Devido ao alto consumo, um controle melhorado, por meio de sensores e controles } \\
\text { automatizados pode trazer economia significativa no consumo de energia (Agarwal } \\
\text { et al., 2010) }\end{array}$ \\
\hline $\begin{array}{l}\text { Sensores em locais de } \\
\text { passagem }\end{array}$ & Evitar luzes acesas desnecessariamente (Roisin et al., 2008) \\
\hline $\begin{array}{l}\text { Película polarizada com } \\
\text { controle de transparência }\end{array}$ & $\begin{array}{l}\text { Assim chamadas janelas "inteligentes" ajudam a controlar a incidência de luz solar, } \\
\text { melhorando a sensação térmica e otimizando o uso de refrigeração e aquecimento } \\
\text { artificiais (Azens \& Granqvist, 2003). }\end{array}$ \\
\hline
\end{tabular}

Figura 3: Tecnologias de automação de edificações

Um estudo demonstrou que inovações ou características avançadas de sustentabilidade podem aumentar o custo total de um projeto de construção e devem ser estimadas independentemente (Morris, 2007). Estudo com profissionais canadenses mostrou que eles percebem que custos são a principal barreira para se investir em práticas verdes (Issa, Rankin, \& Christian, 2010). Por outro lado, segundo o Green Building Council essa visão difere da realidade mostrada em novas pesquisas (WGBC, 2013). Estudos mais recentes constataram queda no custo adicional para se criar edifícios ambientalmente mais sustentáveis: segundo estes estudos estes custos podem girar em média entre 5,1\% a 10,5 \% no custo da construção (Moulin Netto, 2014).

O contexto econômico do país é um fator que pode facilitar ou dificultar as linhas de investimento em eficiência energética das edificações. No caso dos juros praticados estarem altos, este tipo de investimento pode não ser atrativo, devido ao retorno ser menor do que o obtido no mercado financeiro. Esta observação é baseada na teoria de Keynes que "enfatiza a volatilidade das decisões de investimento e sua dependência em relação à eficiência marginal esperada do capital e à taxa de juros" (Melo \& Rodrigues Júnior, 1998).

Outro fator que pode influir na oferta de investimentos desse tipo é o preço da energia: se houver uma tendência de alta, pode haver um crescimento neste tipo de mecanismo, enquanto que em períodos de queda de preços, existirá uma barreira natural para isso, "empurrando" a tendência de liberação de linhas de crédito para baixo (Kumbaroğlu \& Madlener, 2012).

A variação de preços da energia também pode interferir na decisão do proprietário ou administrador do imóvel, viabilizando ou adiando investimentos em reformas voltadas a eficiência energética (Kumbaroğlu \& Madlener, 2012). 


\section{PROCEDIMENTOS METODOLÓGICOS}

A estratégia de pesquisa adotada no trabalho é o Estudo de Caso, tendo por base a abordagem de (Yin, 2015). A pesquisa teve como foco o estudo de uma unidade de análise: Fórum Regional de Pinheiros do Tribunal de Justiça do Estado de São Paulo. No Fórum Regional de Pinheiros (São Paulo) trabalham 341 pessoas e circulam diariamente em torno de 700 usuários. O edifício foi escolhido para esta pesquisa por: (i) ser de propriedade do TJ/SP, o que foi considerado mais apropriado do que escolher um prédio alugado; (ii) ter um porte "médio", ou seja, não é uma exceção como prédio grande, como seria o caso do Fórum João Mendes (São Paulo - SP) nem pequeno demais que não fosse representativo; e (iii) ter usos típicos como salas de audiência, cartórios, ambientes de uso dos funcionários e do público em geral, evitando-se prédios com atividades muito específicas como armazenamento de processos em arquivo morto ou oficinas de manutenção ou prédios com atividades administrativas sem atendimento ao público, que representam exceções.

A trajetória metodológica da pesquisa envolveu o levantamento de dados secundários por meio da análise das plantas dos edifícios e documentos disponibilizados pela instituição, assim como dados primários derivados de entrevistas não estruturadas. Esses dados foram utilizados para a aplicação dos critérios PROCEL-Edifica e a discussão dos resultados visando à proposição de melhorias de eficiência energética do edifício.

\subsection{Fontes de Informação}

De acordo com Yin (2015), em um Estudo de Caso as principais fontes de informação podem ser classificadas em seis categorias. A Figura 4 apresenta como foram utilizadas as categorias nesse estudo.

\begin{tabular}{|c|c|c|c|}
\hline Categorias & Fontes de Informação/equipamentos & Dados Primários & $\begin{array}{l}\text { Dados } \\
\text { Secundários }\end{array}$ \\
\hline Documentos & $\begin{array}{l}\text { Legislação pública, contratos, normas internas do TJ, } \\
\text { manuais de equipamentos, plantas e projetos a } \\
\text { serem fornecidos pela equipe do TJ }\end{array}$ & $\begin{array}{l}\text { Fornecidos pelo TJ/SP } \\
\text { e Secretaria de } \\
\text { Justiça/SP }\end{array}$ & $\begin{array}{l}\text { Buscados na } \\
\text { Internet } \\
\text { (públicos) }\end{array}$ \\
\hline Registros & Relatório de manutenção de equipamentos. & Fornecidos pelo TJ/SP & -- \\
\hline $\begin{array}{l}\text { Entrevistas não } \\
\text { estruturadas }\end{array}$ & $\begin{array}{l}\text { Com usuários, pessoal de engenharia, } \\
\text { administradores e pessoal de empresa certificadora. }\end{array}$ & $\begin{array}{l}\text { TJ/SP e } \\
\text { Secretaria } \\
\text { Justiça/SP }\end{array}$ & $\begin{array}{l}\text { Fundação } \\
\text { Vanzolini } \\
\text { (por e-mail) }\end{array}$ \\
\hline $\begin{array}{l}\text { Observação } \\
\text { direta }\end{array}$ & Visitas & $\begin{array}{l}\text { Ao TJ/SP e Engenharia } \\
\text { da Secretaria de } \\
\text { Justiça/SP }\end{array}$ & -- \\
\hline $\begin{array}{l}\text { Observação } \\
\text { participante }\end{array}$ & Não se aplica & Não trabalha para o TJ & -- \\
\hline Aparatos físicos & $\begin{array}{l}\text { Equipamentos para medições e levantamento de } \\
\text { parâmetros no prédio do TJ-SP especificado. }\end{array}$ & $\begin{array}{l}\text { Trena a Laser, trena e } \\
\text { bússola }\end{array}$ & -- \\
\hline
\end{tabular}

Figura 4: fontes de informações da pesquisa

Uma parte dos dados primários para esta pesquisa foi coletada em 2015, em um estudo prévio para o TJ/SP dentro do convênio firmado com a Universidade num projeto piloto com escopo diferenciado. 
Para a coleta dos demais dados primários citados no Quadro 1 foram feitas várias visitas in loco ao prédio do Fórum de Pinheiros do Tribunal de Justiça de São Paulo e também duas visitas à área de Engenharia da Secretaria de Justiça do Estado (Quadro 1). As entrevistas com os técnicos administrativos foram realizadas de forma não estruturadas e não gravadas, pois o objetivo era recolher informações técnicas e não as percepções dos entrevistados.

As plantas estavam em formato impresso e alguns detalhes de desenhos de engenharia não foram localizados, levando a necessidade de estimar parâmetros, como no caso de materiais de algumas paredes, ou buscar dados junto a fornecedores de materiais, particularmente no caso de vidros, telhas e alguns aparelhos de ar condicionado.

\subsection{Procedimentos de análise de dados}

Foi escolhido o método "prescritivo" do sistema para o tratamento dos dados. Este método então é aplicado a três temas: envoltória, iluminação e ar condicionado.

Envoltória: o edifício foi dividido em dois blocos devido às características apresentadas por este, sendo um bloco denominado "Base" e o outro denominado "Torre". O método foi aplicado para a envoltória de cada bloco, conforme determina o RTQ-C (INMETRO, 2016) e, a partir desses resultados, foi feita a consolidação para a envoltória completa da edificação.

lluminação: as quantidades de lâmpadas e seus respectivos valores de potência foram levantados e, a partir desses valores, foi calculado um valor a ser comparado com tabelas definidas conforme a atividade do edifício, no método denominado "Método das Atividades" do sistema, para se determinar a classificação da lluminação.

Condicionamento de Ar: no caso do edifício em estudo, os aparelhos condicionadores de ar são todos de parede ou o tipo "Split". Dessa forma, o cálculo da etiquetagem para esse tema é feito com base nas eficiências individuais desses aparelhos e de suas capacidades em BTU/h. Então é feita uma consolidação ponderada e determina-se a eficiência geral do conjunto, que resulta na classificação energética para esse tema.

Para a determinação da etiqueta geral, os três temas são tratados por meio de uma fórmula pré-determinada.

Após o uso do método PROCEL-Edifica para determinar o nível de eficiência do prédio como está, foram feitas simulações, variando parâmetros relacionados aos três temas do método, para avaliar como poderia ser melhorado esse nível de eficiência. Esses estudos forneceram subsídios para determinação de melhorias a serem efetuadas no prédio.

As sugestões de melhorias foram analisadas e, por meio de avaliações de custo-benefício e tempo de retorno ("payback") de algumas, foram exemplificada atividades que poderiam servir de base para um plano de ação e determinação de prioridades.

\subsubsection{Aplicação do Método PROCEL-Edifica}


Dois tipos de etiquetagem são trabalhados no PROCEL-Edifica ou PBE-Edifica, com relação à etapa da construção: etiqueta de Projeto ou etiqueta de Edificação Construída, sendo o segundo tipo apropriado ao presente trabalho.

Com relação às características do prédio, o sistema permite avaliar três tipos de etiquetas: envoltória, sistema de iluminação e sistema de ar condicionado. A primeira é obrigatória e deve ser feita para a edificação como um todo, as demais são opcionais e podem ser determinadas para áreas parciais do edifício. Neste estudo foi feita a análise do edifício todo para as três características.

O sistema PROCEL-Edifica permite dois métodos de avaliação: prescritiva ou por simulação computacional. A avaliação prescritiva é menos detalhada, não exige mão de obra especializada, porém atende a maioria dos tipos de edificações. Este foi o método escolhido, não apenas pela facilidade, mas porque permitiria que o aprendizado fosse mais facilmente assimilado pelo pessoal do TJ/SP, visando a multiplicação do estudo em outros edifícios. Os dados devem então ser lançados com uso da equação (1), estabelecida pelo RTQ-C (INMETRO, 2016).

$$
\begin{aligned}
\text { PT }= & 0,30\left\{\text { EqNumEnv } \frac{\mathrm{AC}}{\mathrm{AU}}+\frac{5 \mathrm{APT}}{\mathrm{AU}}+\frac{\mathrm{ANC}}{\mathrm{AU}} \text { EqNumV }\right\}+0,30 \text { EqNumDPI }+ \\
& +0,40\left\{\text { EqNumCA } \frac{\mathrm{AC}}{\mathrm{AU}}+\frac{5 \mathrm{APT}}{\mathrm{AU}}+\frac{\mathrm{ANC}}{\mathrm{AU}} \text { EqNumV }\right\}+\mathrm{b}
\end{aligned}
$$

Onde:

- $A C(m 2)$ é a área útil dos ambientes climatizados;

- $\mathrm{AU}(\mathrm{m} 2)$ é a área útil total;

- EqNumEnv (valor numérico): equivalente numérico da envoltória;

- EqNumDPI (valor numérico): equivalente numérico do sistema de iluminação, identificado pela sigla DPI (Densidade de Potência de lluminação);

- EqNumCA (valor numérico) equivalente numérico do sistema de condicionamento de ar;

- $\mathrm{APT}(\mathrm{m} 2)$ representa a área útil dos ambientes de permanência transitória, desde que não climatizados;

- ANC (m2) representa a área útil dos ambientes não climatizados de permanência prolongada*;

- EqNumV (valor numérico) é o equivalente numérico de ambientes não climatizados e/ou ventilados naturalmente;

- $\quad$ b (valor numérico) representa a pontuação obtida pelas bonificações, que pode variar de zero a 1. 
Para determinação do EqNumV em edifícios com ventilação natural ou áreas de permanência prolongada sem condicionamento artificial, é necessário comprovar uma porcentagem de horas dentro da zona de conforto por ventilação natural (POC) nestes ambientes, por meio de simulação, segundo o RTQ-C, pag. 198 (INMETRO, 2016).

A Envoltória do edifício é composta de todas as fachadas do edifício e a cobertura. 0 indicador de consumo da envoltória (ICenv) define o quanto a envoltória afeta o consumo energético da edificação. Depende da geometria do prédio, da abertura das fachadas, do tipo de vidro utilizado nas fachadas, dos ângulos verticais e horizontais de sombreamento, da área de projeção do prédio e da zona bioclimática em que este se encontra (Carlo \& Lamberts, 2010).

A partir dos parâmetros do edifício, é feito o cálculo do ICenv por fórmulas pré-definidas pelo método. Variando-se esses parâmetros para valores pré-validados, é possível determinar o Índice de consumo mínimo da envoltória (ICmin) , valor de uma envoltória altamente eficiente, determinada por estudo anterior (Carlo, 2008) e o índice de consumo máximo para o nível D do PROCEL-Edifica (ICmáxD), com características tabeladas determinadas igualmente por estudo anterior (Carlo, 2008). Então o ICenv é comparado com esses limites e é determinada a classificação PROCEL-Edifica da Envoltória (INMETRO, 2016).

Após a classificação, os pré-requisitos devem ser verificados, de acordo com a classe obtida, para valores de transmitância térmica e absorbâncias de paredes e coberturas e valor de abertura zenital (INMETRO, 2016).

Quanto ao sistema de iluminação, segundo o RTQ-C, (INMETRO, 2016) a eficiência do sistema de iluminação pode ser calculada por dois métodos: método das áreas e o método das atividades. Para o cálculo da eficiência do sistema de iluminação foi escolhido o método das áreas. Devido a inexistência da categoria "fórum" na tabela de atividades, foram realizadas duas alternativas - "Prefeituras / Instituições Governamentais" e "Tribunais". Ressalte-se que não ocorrem julgamentos com júri no edifício, somente com presença de juízes.

Quanto ao quesito condicionamento de ar, foram identificados os aparelhos, andar por andar, por meio de verificações in loco e, quando necessárias, análises dos documentos fornecidos pelo TJ/SP. Para efeito de aproximação, quando não foi possível se determinar a performance energética de um aparelho, foi assumido o pior caso, isto é, a classificação " $E$ " no sistema PROCEL para este tipo de equipamento, que corresponde para efeito de cálculo ao equivalente numérico $=1$.

A classificação do condicionamento de ar do edifício, para prédios somente com condicionadores do tipo janela ou split, é dada pela média ponderada dos equivalentes numéricos das classificações PROCEL dos aparelhos utilizados e das capacidades destes em BTU/h (INMETRO, 2016).

Para estabelecer as zonas térmicas do prédio, foi realizado levantamento dos aparelhos de ar condicionado (todos de "janela" ou tipo split), áreas de circulação (permanência temporária) e áreas de permanência prolongada sem condicionamento artificial.

\subsection{Análise do resultado do PROCEL-Edifica e estudo de melhorias}

Após determinação do resultado da etiquetagem, por meio de variação de parâmetros do método PROCEL-Edifica e com base na literatura, foram identificados potenciais temas de 
intervenção e ações técnicas visando melhoria da eficiência energética do edifício. A título de exploração e geração de ideias-exemplo, foram obtidos orçamentos junto a fornecedores do mercado para analisar a viabilidade de ações que podem ser implantadas visando a eficiência energética. A partir destes orçamentos foram efetuadas análises de custo $\mathrm{x}$ benefícios, pelo método do tempo de retorno do investimento (payback), que podem servir de base para priorização de ações.

\section{DESCRIÇÃO DO CASO}

O TJ/SP é uma instituição que opera em 704 prédios, próprios ou alugados, espalhados por todo o estado. Cada prédio é administrado em seu dia-a-dia por pessoal que trabalha no próprio edifício, dedicado às atividades de operação, manutenção, limpeza, etc. Algumas exceções são contratos centralizados de maneira "corporativa", tais como terceirização de impressoras, helpdesk de TI, coleta de resíduos sólidos nos diversos edifícios da Cidade de São Paulo.

No caso do prédio em estudo, a equipe administrativa conta com uma coordenação, assistentes administrativos e um funcionário operacional prático formação específica. Nenhum dos funcionários da administração do edifício tem formação técnica superior, como engenharia, arquitetura ou tecnologia. Estruturas semelhantes existem na maioria dos prédios da instituição. O suporte técnico especializado é oferecido por uma área central de engenharia.

A Figura 5a mostra uma perspectiva do edifício em estudo. É composto de seis andares padrão, mais pavimentos térreo e subsolo. Possui duas fachadas no Térreo totalmente envidraçadas na frente e no fundo, e nos andares da torre as quatro fachadas são parcialmente envidraçadas, todas com vidros de $6 \mathrm{~mm}$ bronze, da marca Cebrace. O pavimento térreo possui uma cobertura de vegetação em sua laje. Subsolo é parcialmente enterrado, sendo a maior parte garagem e com praticamente nenhuma parede em contato com o exterior. A Figura $5 b$ ilustra a Orientação solar do Edifício. A face correspondente a Rua Costa Lôbo é considerada a face Norte, uma vez que a diferença de $30^{\circ}$ em relação ao Norte é aceita pelo regulamento do PROCEL-Edifica.

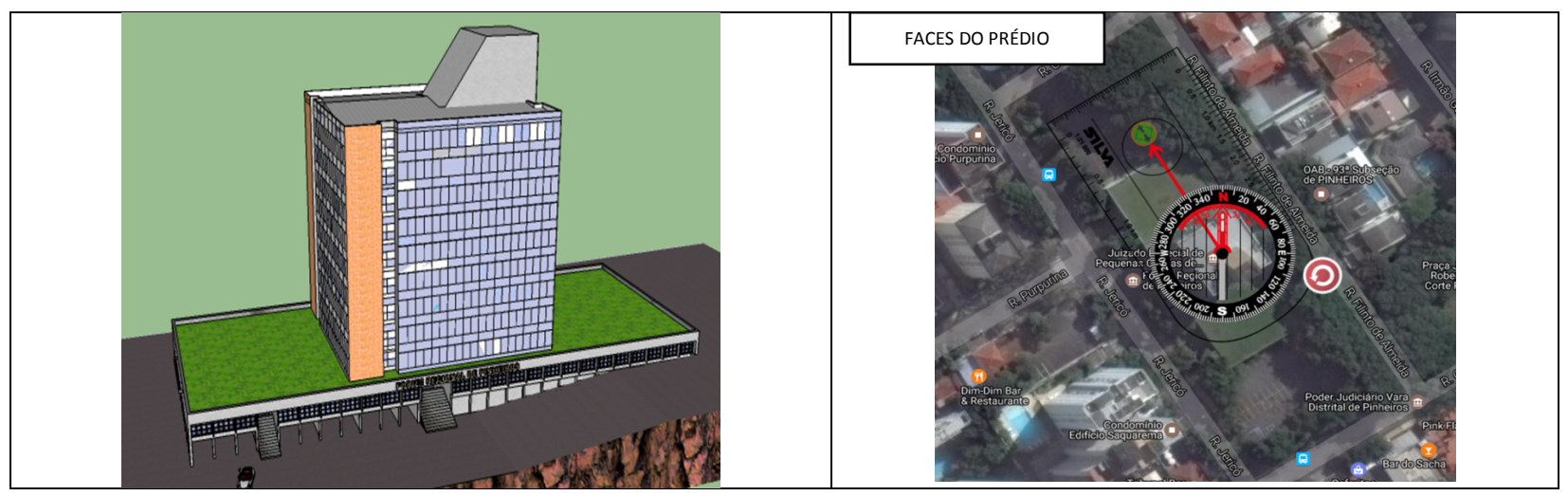

Figura 5a: Desenho do edifício sem escala. Fonte Autores
Figura 5b: Posicionamento do prédio. Fonte Autores. Imagem do Google Maps. 
A Figura 6 mostra o exemplo do quinto andar, como andar "padrão".

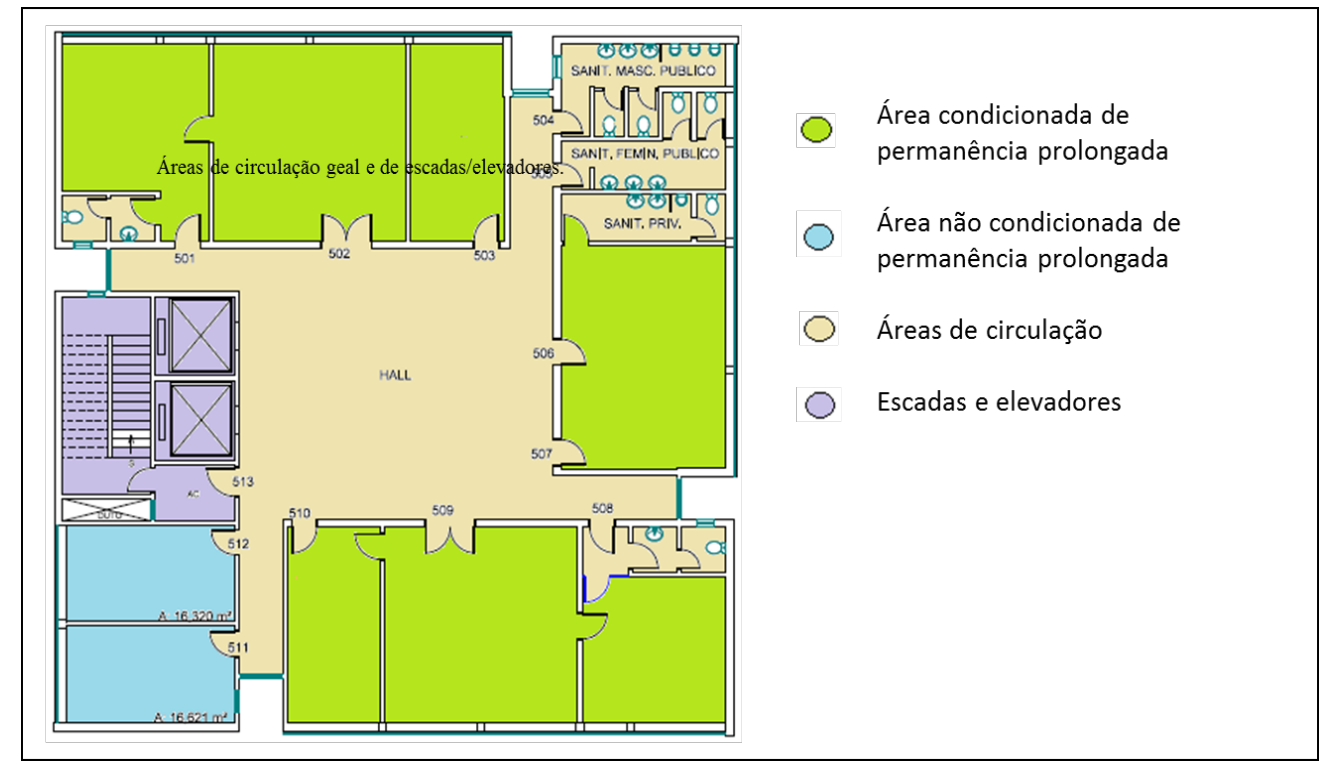

Figura 6: Planta do quinto andar, como andar "padrão", com áreas por categoria

Foram realizadas 5 visitas, no período de outubro a dezembro de 2015. Nessas visitas foram obtidas informações sobre lâmpadas e aparelhos de ar condicionado (tipo, potência e localização, quantidade) e foram verificados os usos das áreas e o layout real verificado contra as plantas. Foram ainda tomadas as medidas que não constavam em desenho e foram verificados in loco os materiais de construção. Adicionalmente, foram feitas duas visitas ao Departamento de Engenharia - Secretaria de Justiça do Estado de São Paulo para obtenção de dados de plantas e desenhos de engenharia, para consulta a plantas e desenhos de engenharia.

\section{RESULTADOS}

A fim de possibilitar a aplicação do método prescritivo, o prédio foi dividido em três blocos, conforme mostra a Figura 7, sendo a classificação calculada para cada um deles.

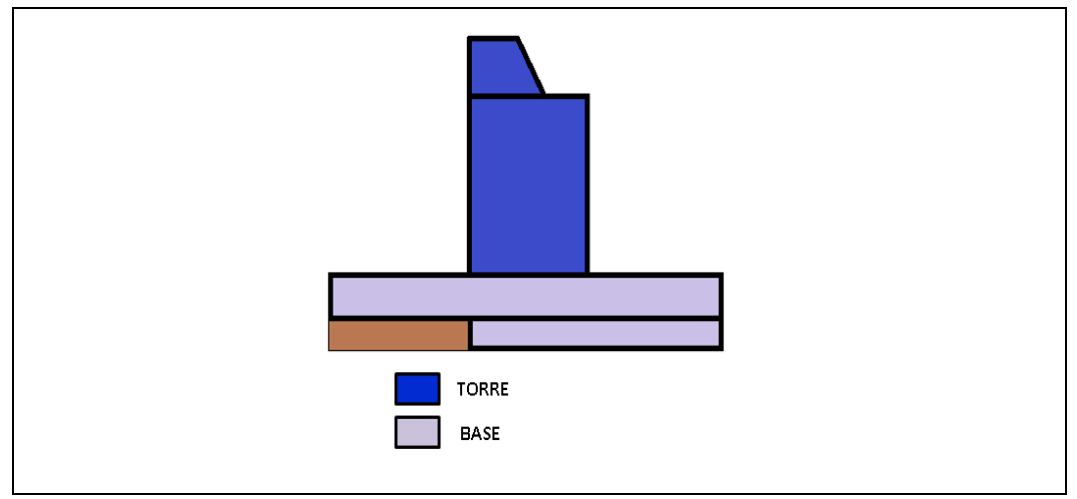

Figura 7: Divisão do edifício em blocos para aplicação do método

Em relação ao condicionamento de ar, foram identificados no total 38 aparelhos de ar condicionado, com potências variando entre 7500 e 48000 BTU/h, e categorias PROCEL 
identificadas A, B, C e D, sendo 3 aparelhos sem categoria definida classificados como $E$. Dois aparelhos de ar condicionado portáteis não foram considerados nos cálculos, por não pertencer a estrutura da edificação.

A Figura 8 mostra os resultados dos parâmetros a serem usados na Equação 1.

\begin{tabular}{|l|l|l|}
\hline Parâmetro & Descrição & Valor encontrado \\
\hline AC & $\begin{array}{l}\text { Total área condicionada em ambientes de permanência } \\
\text { prolongada }\end{array}$ & $1288,71 \mathrm{~m}^{2}$ \\
\hline AU & Total área útil do edifício & $4658,47 \mathrm{~m}^{2}$ \\
\hline APT & Total área útil de permanência transitória & $1921,08 \mathrm{~m}^{2}$ \\
\hline ANC & $\begin{array}{l}\text { Total área útil de ambientes não climatizados de permanência } \\
\text { prolongada }\end{array}$ & $1430,86 \mathrm{~m}^{2}$ \\
\hline
\end{tabular}

Figura 8: Dados-chave do edifício

A Figura 9 mostra os resultados do Equivalente numérico para aplicação da Equação 1.

\begin{tabular}{|l|l|c|l|}
\hline Parâmetro & Descrição & Valor & Observação \\
\hline EqNumEnv & $\begin{array}{l}\text { Equivalente numérico } \\
\text { calculado da envoltória (Base } \\
\text { Classe D, Torre Classe D) }\end{array}$ & 2 & $\begin{array}{l}\text { Para análise o prédio foi dividido em } \\
\text { torre e base. As duas obtiveram classe D. }\end{array}$ \\
\hline EqNumDPI & $\begin{array}{l}\text { Equivalente numérico } \\
\text { calculado da iluminação } \\
\text { (Densidade de Potência de } \\
\text { lluminação, Classe C) }\end{array}$ & 3 & $\begin{array}{l}\text { Por meio do método das atividades, para } \\
\text { atividades de Instituições } \\
\text { Governamentais" e "Tribunais" }\end{array}$ \\
\hline EqNumCA & $\begin{array}{l}\text { Equivalente numérico } \\
\text { calculado do condicionamento } \\
\text { de ar(Classe B) }\end{array}$ & 4 & $\begin{array}{l}\text { Levando-se em conta os níveis de } \\
\text { performance dos aparelhos. }\end{array}$ \\
\hline EqNumV & $\begin{array}{l}\text { Equivalente numérico } \\
\text { ventilação natural * }\end{array}$ & 0 & $\begin{array}{l}\text { Não considerados os ambientes não } \\
\text { ventilados, pois não há estudo de } \\
\text { conforto térmico e simulação }\end{array}$ \\
\hline PT & Bonificações & 0 & $\begin{array}{l}\text { Nenhuma prática que levasse a } \\
\text { bonificação }\end{array}$ \\
\hline
\end{tabular}

Figura 9: Parâmetros da Equação 1

Os critérios de etiqueta, de acordo com a pontuação recebida, tendo como referência o regulamento do sistema de etiquetagem, são mostrados na Figura 10.

\begin{tabular}{c|c}
\hline Classificação Final & Pontuação Total \\
\hline A & $>=4,5 \mathrm{a} 5$ \\
\hline B & $>=3,5 \mathrm{a}<4,5$ \\
\hline C & $>=2,5 \mathrm{a}<3,5$ \\
\hline D & $>=1,5 \mathrm{a}<2,5$ \\
\hline E & $<1,5$ \\
\hline
\end{tabular}

Figura 10: Classificação final a ser aplicada sobre o resultado da fórmula ponderada, segundo o regulamento do INMETRO. 
Portanto, a classificação Geral do edifício no PROCEL-Edifica, de acordo com o método Prescritivo, para a pontuação total 2,951, é Etiqueta ENCE "C".

Uma limitação do trabalho é que não foi possível fazer a simulação para determinação do Equivalente Numérico de Ambientes não climatizados de permanência prolongada (EqNumV). Para contornar a limitação, foram feitos cálculos de avaliação para o melhor e o pior caso e foram obtidos: no pior caso, com EqNumV $=1$, o resultado da classificação geral foi $C$, portanto inalterado. No melhor caso, com EqNumV= 5, o resultado foi $B$.

Por fim, a classificação de cada um dos blocos e do prédio como um todo foi analisada contra a existência de pré-requisitos para cada uma das categorias, a fim de confirmar o resultado numérico. A Figura 11 apresenta esses resultados.

\begin{tabular}{|c|c|c|c|c|c|c|}
\hline Tema & Detalhes & $\begin{array}{l}\text { Resultado ou } \\
\text { critério }\end{array}$ & $\begin{array}{l}\text { Classificação } \\
\text { Calculada } \\
\text { Procel- } \\
\text { Edifica }\end{array}$ & Pré-requisito & $\begin{array}{l}\text { Atendi- } \\
\text { mento } \\
\text { Pré- } \\
\text { Requisi- } \\
\text { tos }\end{array}$ & $\begin{array}{l}\text { Classi- } \\
\text { ficação } \\
\text { Final }\end{array}$ \\
\hline \multirow{3}{*}{ Envoltória } & Base & 131,68 & D & \begin{tabular}{l}
\multicolumn{2}{l}{ Transmitância } \\
térmica de \\
paredes \\
cobertura
\end{tabular} & Sim & \multirow{3}{*}{ D } \\
\hline & Torre & 281,59 & D & \begin{tabular}{lr}
\multicolumn{2}{l}{ Transmitância } \\
térmica de \\
paredes \\
cobertura
\end{tabular} & Sim & \\
\hline & $\begin{array}{c}\text { Prédio } \\
\text { completo }\end{array}$ & -- & D & -- & -- & \\
\hline \multirow[b]{2}{*}{ Iluminação } & \multirow{2}{*}{$\begin{array}{c}\text { Avaliação } \\
\text { potência } \\
\text { de } \\
\text { iluminação }\end{array}$} & $\begin{array}{c}\text { Prefeituras- } \\
\text { Instituições } \\
\text { Governamentais }\end{array}$ & C & $\begin{array}{l}\text { Divisão circuitos } \\
\text { por função }\end{array}$ & Sim & \multirow[b]{2}{*}{$C$} \\
\hline & & Tribunais & B & $\begin{array}{l}\text { Divisão circuitos } \\
\text { por função e } \\
\text { Aproveitamento } \\
\text { da luz natural }\end{array}$ & Sim/Não & \\
\hline $\begin{array}{l}\text { Ar } \\
\text { condicionado }\end{array}$ & $\begin{array}{c}\text { Eficiência } \\
\text { dos } \\
\text { aparelhos } \\
\text { individuais } \\
\end{array}$ & $\begin{array}{l}\text { Aparelhos tipo } \\
\text { Split e de Janelas }\end{array}$ & B & -- & -- & B \\
\hline $\begin{array}{l}\text { Classificação } \\
\text { Geral do Prédio }\end{array}$ & $\begin{array}{c}\text { Envoltória } \\
+ \\
\text { Iluminação } \\
+ \\
\text { Condiciona } \\
\text {-mento de } \\
\text { Ar }\end{array}$ & $\begin{array}{l}\text { Resultado Global } \\
\quad=2,95\end{array}$ & C & -- & -- & C \\
\hline
\end{tabular}

Figura 11: Quadro síntese dos resultados encontrados

\section{DISCUSSÃO}

\subsection{Aspectos positivos}


Os resultados apresentados permitem algumas considerações a respeito de aspectos positivos verificados no edifício, em relação à Eficiência Energética e avaliada pelo método Prescritivo (PROCEL-Edifica).

Os aparelhos de Ar Condicionado verificados, em sua maioria, tem eficiência energética comprovada pelo PROCEL como A ou B, o que ajudou a conseguir a classificação B para o sistema, da edificação como um todo. Isto demonstra a conscientização dos administradores do prédio em relação à necessidade de se reduzir o consumo de energia causado por esses equipamentos. Existem ainda aparelhos de ar condicionado antigos e/ou sem classificação definida, que podem ser substituídos por equipamentos mais modernos e com avaliação A ou B no PROCEL, para ajudar na melhoria da eficiência Em relação ao número de aparelhos de ar condicionado, no decorrer da pesquisa alguns usuários reclamaram de desconforto térmico e, pela avaliação do PROCEL-Edifica, existe margem para aumentar a quantidade destes aparelhos, desde que instalados equipamentos eficientes (A ou B), para não reduzir a classificação atual.

Outro ponto positivo encontrado foi a preocupação com a troca das lâmpadas fluorescentes por tipo LED, conforme indicado por (Krarti, 2015), que trabalham com menor potência, consumindo menos energia elétrica sem afetar a iluminância, mantendo o conforto visual dos ocupantes.

Essas medidas positivas no consumo de energia elétrica poderiam trazer uma melhoria na avaliação do PROCEL-Edifica. Com uma redução de $10 \%$ a $12 \%$ no consumo de eletricidade, já haveria uma mudança para melhor de classificação PROCEL-Edifica. Note-se que isso só acontece se forem atendidos os pré-requisitos do RTQ-C (INMETRO, 2016).

A envoltória da Base do prédio tem um aspecto bastante relevante em termos de técnicas passivas de resfriamento, que é a cobertura "verde". Esse telhado é composto de cobertura de terra e grama e elementos impermeabilizantes sobre a laje do piso térreo. Esta característica faz com que, segundo Ferreira (2009) e (Castleton, Stovin, Beck, \& Davison, 2010)), haja um melhor resfriamento, filtrando a radiação incidente no edifício e no inverno colaborando com o aquecimento natural. Como cobre mais de $2 / 3$ do telhado, faz com que o pré-requisito de absorbância térmica seja atendido no método do PROCEL-Edifica (INMETRO, 2016) sem rebaixar a classificação do prédio.

\subsection{Oportunidades de melhoria}

Foram listadas as possíveis melhorias relacionadas a Eficiência Energética no edifício, após avaliação pelo método do PROCEL-Edifica, e apresentadas na Figura 12.

\begin{tabular}{|l|l|l|l|}
\hline Proposta & Efeito & Vantagens & Desvantagens \\
\hline $\begin{array}{l}\text { Substituição de lâmpadas } \\
\text { fluorescentes por tipo LED (J. } \\
\text { Z. Ferreira, 2014) }\end{array}$ & $\begin{array}{l}\text { Redução } 55 \% \text { no } \\
\text { lonsumo. } \\
\text { Aolongo do tempo pode } \\
\text { melhorar a classificação } \\
\text { PROCEL-Edifica. }\end{array}$ & $\begin{array}{l}\text { Menor consumo, maior } \\
\text { durabilidade. } \\
\text { Pode ser feito aos poucos. } \\
\text { Tempostimento baixo. de retorno do }\end{array}$ & $\begin{array}{l}\text { Custo um pouco } \\
\text { maior que as } \\
\text { fluorescentes. }\end{array}$ \\
\hline
\end{tabular}




\begin{tabular}{|c|c|c|c|}
\hline Proposta & Efeito & Vantagens & Desvantagens \\
\hline & & Investimento baixo. & \\
\hline 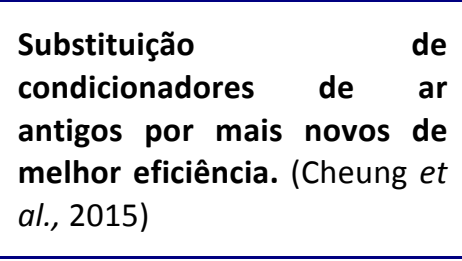 & $\begin{array}{l}\text { Aumento do nível de } \\
\text { eficiência energética do } \\
\text { condicionamento de ar. }\end{array}$ & $\begin{array}{l}\text { Redução de consumo. } \\
\text { Pode haver ganho de } \\
\text { conforto térmico para os } \\
\text { usuários } \\
\text { Pode ser implementado aos } \\
\text { poucos. }\end{array}$ & $\begin{array}{l}\text { Investimento a ser } \\
\text { feito. }\end{array}$ \\
\hline $\begin{array}{l}\text { Utilização de dispositivos } \\
\text { para melhorar o Fator Solar } \\
\text { dos vidros (Película ou } \\
\text { Persianas) (Pereira, 2010) } \\
\end{array}$ & $\begin{array}{l}\text { Aumento da classificação } \\
\text { no PROCEL-Edifica. }\end{array}$ & $\begin{array}{l}\text { Melhorar conforto térmico e } \\
\text { reduzir gasto com } \\
\text { condicionamento de ar. }\end{array}$ & $\begin{array}{l}\text { Investimento a ser } \\
\text { feito } \\
\text { levantado) }\end{array}$ \\
\hline $\begin{array}{l}\text { Alterações nas aberturas das } \\
\text { Fachadas }\end{array}$ & $\begin{array}{l}\text { Aumento da classificação } \\
\text { no PROCEL-Edifica. }\end{array}$ & $\begin{array}{l}\text { Conforto térmico melhor e } \\
\text { redução gasto com } \\
\text { condicionamento de ar. }\end{array}$ & $\begin{array}{lr}\text { Dificuldades } & \\
\text { inerentes } & \text { a } \\
\text { reformas } & \text { em } \\
\text { prédios } & \text { já } \\
\text { existentes. } & \\
\end{array}$ \\
\hline $\begin{array}{l}\text { Utilização de sensores de luz } \\
\text { nas áreas de permanência } \\
\text { temporária (Roisin et al., } \\
\text { 2008) }\end{array}$ & Racionalização no uso. & $\begin{array}{l}\text { Redução no consumo de } \\
\text { energia. }\end{array}$ & $\begin{array}{l}\text { Depende do fluxo } \\
\text { de pessoas nos } \\
\text { locais, se for alto a } \\
\text { vantagem } \\
\text { pequena. }\end{array}$ \\
\hline $\begin{array}{l}\text { Mudança nos circuitos das } \\
\text { lâmpadas das salas de } \\
\text { permanência prolongada } \\
\text { para aproveitamento } \\
\text { iluminação natural (Ghisi \& } \\
\text { Lamberts, 1997) }\end{array}$ & $\begin{array}{ll}\text { Atendimento } & \text { a Pré- } \\
\text { Requisito } & \text { PROCEL- } \\
\text { Edifica. } & \end{array}$ & $\begin{array}{l}\text { Economia de energia, } \\
\text { racionalização de uso. } \\
\text { Melhoria na classificação } \\
\text { PROCEL-Edifica no quesito } \\
\text { lluminação. }\end{array}$ & $\begin{array}{l}\text { Investimento a ser } \\
\text { feito (Médio a Alto). }\end{array}$ \\
\hline $\begin{array}{l}\text { Uso de elementos que } \\
\text { melhorem o sombreamento } \\
\text { vertical da Torre e da Base, } \\
\text { brises ou outros elementos } \\
\text { (Venâncio \& Pedrini, 2008). }\end{array}$ & $\begin{array}{l}\text { Aumento da classificação } \\
\text { no PROCEL-Edifica }\end{array}$ & $\begin{array}{l}\text { Melhorar conforto térmico e } \\
\text { reduzir consumo de } \\
\text { condicionamento de ar. }\end{array}$ & $\begin{array}{l}\text { Mudança no projeto } \\
\text { original. } \\
\text { Necessidade de } \\
\text { investimento (não } \\
\text { levantado) }\end{array}$ \\
\hline $\begin{array}{l}\text { Automação de aparelhos de } \\
\text { ar condicionado (Yang \& } \\
\text { Becerik-Gerber, 2014) }\end{array}$ & $\begin{array}{l}\text { Melhor controle. } \\
\text { Estabelecer temperatura } \\
\text { de setup padrão }\end{array}$ & Redução de desperdícios, & $\begin{array}{l}\text { Investimento médio } \\
\text { a alto. }\end{array}$ \\
\hline $\begin{array}{l}\text { Automação da lluminação } \\
\text { nos ambientes de } \\
\text { permanência prolongada (Li, } \\
2013 \text { ) }\end{array}$ & $\begin{array}{l}\text { Independência } \\
\text { usuário. }\end{array}$ & $\begin{array}{l}\text { Redução de desperdícios, } \\
\text { controle mais efetivo, } \\
\text { independência do usuário } \\
\text { ou facilitada para ele. Uso } \\
\text { de power-off geral. }\end{array}$ & $\begin{array}{l}\text { Investimento médio } \\
\text { a alto. }\end{array}$ \\
\hline
\end{tabular}




\begin{tabular}{|c|c|c|c|}
\hline Proposta & Efeito & Vantagens & Desvantagens \\
\hline $\begin{array}{l}\text { Uso de luz solar "encanada" } \\
\text { para o térreo (Jenkins \& } \\
\text { Muneer, 2003) }\end{array}$ & $\begin{array}{l}\text { Substitui lâmpada } \\
\text { incandescente de } 100 \mathrm{~W}\end{array}$ & $\begin{array}{l}\text { Substitui algumas lâmpadas } \\
\text { em ambientes de } \\
\text { permanência temporária } \\
\text { como corredores } \\
\text { banheiros, ajudando na } \\
\text { redução do consumo de } \\
\text { energia elétrica. }\end{array}$ & $\begin{array}{l}\text { No período noturno } \\
\text { é necessária uma } \\
\text { iluminação de } \\
\text { backup. } \\
\text { Investimento } \\
\text { Médio. } \\
\text { Necessária furação } \\
\text { em laje. }\end{array}$ \\
\hline
\end{tabular}

Figura 12: figu voltadas à eficiência energética

Estas alternativas podem servir como base para os gestores avaliarem vantagens e desvantagens em implantar as sugestões levantadas pelo estudo. Uma das questões importantes para a gestão é que a administração do edifício tem autonomia limitada para execução de melhorias. Essa autonomia limitada está relacionada a fatores técnicos, uma vez que a assistência de engenharia é realizada por uma área centralizada do TJSP, quanto porque podem existir projetos de reforma já em elaboração. Também está relacionada a fatores financeiros, dado que os investimentos também precisam ser aprovados por áreas centralizadas.

Outras melhorias poderiam ser incluídas, como por exemplo a utilização local de fontes alternativas de energia tipo painéis fotovoltaicos e geradores eólicos. Porém, como estas não estão nos cálculos do método a não ser nas bonificações, e implicam geralmente em altos investimentos, não foram incluídas no Quadro 6 e tratadas no estudo.

\section{3 retorno do investimento}

Para duas melhorias foram calculados os valores e o retorno de investimento (payback) no momento do estudo, a título de exemplos.

a) Iluminação Natural: uma simulação para o aproveitamento da luz natural com a divisão de circuitos de iluminação internos das salas foi feita para o edifício estudado. Esta divisão é um dos pré-requisitos do RTQ-C para classificação níveis A e B (INMETRO, 2016). Utilizando um único orçamento de mercado, como exemplo, no valor de $\mathrm{R} \$ 44.500$, resultou num tempo de retorno do investimento de 2,75 anos, sem considerar nenhuma taxa de juros, ou 3,63 anos utilizando como taxa de desconto 13\%, que correspondia aproximadamente à taxa referencial de juros básica da economia - taxa SELIC (Banco Central do Brasil, 2017) à época do estudo.

b) Substituição de lâmpadas: foi realizada uma estimativa de custo da substituição de lâmpadas fluorescentes por LED, utilizando-se como base a lâmpada fluorescente $40 \mathrm{~W}$ (R\$ 7,50 (http://www.yamamura.com.br/lampada-fluorescente-t10-de-40w-osram-219423.aspx/p, acessado em 10, fevereiro, 2017) e a lâmpada LED 18W (R\$ 17,37, preço real pago pelo TJ-SP conforme registros). Supondo que as lâmpadas fiquem ligadas $12 \mathrm{~h}$ por dia, 30 dias por mês e que o valor do KWh para o TJ/SP é $\mathrm{R} \$$ 0,49, o tempo de retorno simples dessa troca pode ser estimado em aproximadamente 2,55 meses ou usando a taxa SELIC da época do estudo como 
referência (13\% / ano), o tempo de retorno descontado vai a 2,60 meses, ou seja, menos de três meses nos dois casos.

\subsection{Análise de uso do método Prescritivo do PROCEL-Edifica}

O Método Prescritivo permite a análise da EEE mesmo sem utilizar recursos sofisticados de software e equipamentos, a partir de levantamento de dados necessários para isso. Esses dados, uma vez obtidos, permitem a uma pessoa com pouca "expertise" fazer os cálculos.

A grande dificuldade encontrada na pesquisa foi a obtenção desses dados. Devido a idade do prédio em estudo (35 anos), alguns documentos referentes à construção, como o memorial descritivo com os detalhamentos da obra, foram perdidos.

As plantas foram fornecidas em formato eletrônico com a extensão PDF e sem cotas. Com isso, foram necessárias inúmeras medições em desenhos neste formato ou consulta a plantas impressas, às vezes de difícil leitura, em formato grande ( $\mathrm{O} O$ ou maior), nem sempre muito nítidas, que necessitaram ser fotografadas e as fotos depois consultadas.

As transmitâncias das paredes foram calculadas a partir de informações dos detalhes construtivos de um funcionário antigo do TJ/SP-Pinheiros encarregado da zeladoria do prédio, que conhecia a constituição das paredes, aproximação essa assumida como verdadeira, por não haver documentação disponível para comprovação e não foi permitido perfurar as paredes do edifício.

O conforto térmico dos ocupantes somente foi considerado nas áreas não condicionadas, de acordo com o método Prescritivo do PROCEL-Edifica. A área condicionada estaria $100 \%$ do tempo em conforto? Existem questões, por exemplo, de expectativas pessoais e de desconfortos pontuais (um exemplo é quem fica na saída da tubulação do ar condicionado), conforme mostra estudo de (Gou, Lau, \& Chen, 2012)). As expectativas pessoais têm a ver com a questão relativa ao controle manual dos aparelhos, em que as decisões pessoais relacionadas à sensação térmica, nem sempre unânimes, fiquem a cargo dos usuários. Essas questões não são levadas em conta nessa certificação.

O método do Procel-Edifica trabalha com indicadores de ativos, isto é, utiliza na sua avaliação as características do prédio, independente de sua ocupação. Não é objetivo da certificação avaliar o operacional do edifício. Não leva em conta as atitudes dos usuários com relação à economia de energia ou gasto excessivo (por exemplo ar condicionados ligados após o expediente ou nos finais de semana). Além disso, a etiqueta de Edificação Construída não tem prazo de validade. Como saber se o prédio efetivamente será eficiente ao longo do tempo e como o gerenciamento e as atitudes dos usuários influenciarão nessa eficiência? Seriam necessárias avaliações periódicas de eficiência energética do prédio, utilizando outro sistema que trabalhe com indicadores operacionais, para permitir obter uma melhor caracterização durante seu ciclo de vida (Neumann \& Jacob, 2008).

Os órgãos públicos, segundo informações levantadas por e-mail junto a Fundação Vanzolini, são os que estão procurando mais a etiquetagem para edifícios novos ou reformas de antigos, devido a obrigatoriedade da norma. Nota-se também, segundo a mesma fonte, um aumento na procura da etiquetagem voluntária para prédios particulares. 
A maneira como o usuário se comporta pode ter efeito significativo no consumo de energia elétrica de uma edificação, mesmo o que recebeu boa classificação pelo PROCEL-Edifica, tanto na etiqueta de projeto como de edificação construída. A Eficiência Energética pode ficar comprometida com atitudes de desperdício de energia elétrica, bem como uma edificação com classificação não tão boa pode conseguir melhorar seu desempenho real se os seus ocupantes tomarem atitudes voltadas a minimizar o consumo energético (Didoné, 2009).

Para fazer uma avaliação mais adequada, além das características do prédio, avaliadas por Indicadores de Ativos como os do PROCEL-Edifica, são necessárias medições ao longo do tempo por meio de Indicadores Operacionais, que partem de medidas reais de uso de energia e as comparam com edificações da mesma natureza e características para obter o seu grau de eficiência energética (Goldstein \& Eley, 2014).

Geralmente as políticas de eficiência energética procuram trabalhar com sistemas de classificação que utilizam indicadores operacionais ao invés de métodos simulados. Alguns motivos para isso podem ser custos mais baixos, maior simplicidade e facilidade de acompanhamento periódico do resultado. O outro lado é a dependência dos resultados das práticas operacionais adotadas para operar o edifício, dificultando sua comparação com outros (Leipziger, 2013).

Existe uma tendência, segundo (Mo et al., 2010) da utilização dos dois métodos em conjunto e aparentemente os métodos de classificação caminham para isso. Estes permitem melhor acompanhamento de desempenho (pelos indicadores operacionais) e uma avaliação do desempenho do edifício fisicamente mais apurada (modelos simulados). Porém não é fácil conciliar as duas abordagens, como citado por (Mo et al., 2010) a respeito do sistema chinês MOHURD. Para se fazer aproximação dos dois "ratings", operacional e calculado (simulado) é necessário uma calibração para compartilhamento de premissas, métricas e metodologias. Alguns sistemas estão tentando fazer essa conciliação, requerendo a integração dos dois ratings, como citado acima.

Uma ferramenta online de cálculo para o método prescritivo, chamada WebPrescritivo, é disponibilizada no sitio do Laboratório de Eficiência Energética da Universidade Federal de Santa Catarina (http://www.labeee.ufsc.br/sites/default/files/webprescritivo/index.html). Permite uma avaliação rápida da Eficiência Energética de um edifício, usando o método do PROCEL-Edifica, sem a necessidade de muitos cálculos. É necessário preencher os parâmetros e ele gera o resultado a partir da equação determinada e de parâmetros verificados. Tem como principal desvantagem o fato de não permitir a divisão do edifício em blocos, quando necessário, como é o caso estudado no presente trabalho. Além disso, vários dos cálculos tem de ser realizados em separado, de maneira não automatizada, exigindo expertise do usuário. Algumas verificações de resultados de variações de parâmetros foram facilitadas no estudo por esta ferramenta.

Uma questão importante para a instituição TJ/SP é a possibilidade de replicação do estudo. Embora o método "prescritivo" utilizado seja relativamente simples, requer uma série de escolhas técnicas que são difíceis para pessoal administrativo sem conhecimento em engenharia, arquitetura ou tecnologia. Como consequência para a gestão, a aplicação deste método requer apoio de pessoal com formação apropriada, que não está disponível diretamente nos edifícios mas apenas nas áreas centralizadas. 


\section{CONCLUSÕES}

O estudo mostrou que, segundo o método prescritivo do PROCEL-Edifica, a eficiência do condicionamento de ar da edificação está de acordo com a classificação B e a iluminação com a classificação C. A classificação da envoltória envolveu dois blocos distintos: a Torre e a Base do prédio, sendo que a Torre obteve classificação $D$ e a Base também classificação $D$; portanto o índice médio obtido foi o D. No cálculo completo o prédio obteve a Etiqueta Geral C.

$\mathrm{O}$ estudo mostrou que algumas medidas importantes foram adotadas no TJ/SP-Pinheiros e ajudaram na classificação do prédio em relação ao consumo energético, como o telhado "verde" na cobertura do térreo e os aparelhos de ar condicionado com bom coeficiente de desempenho pelo PROCEL. Uma ação a ser ressaltada, apesar de ainda não ter influenciado os cálculos do método, é o comprometimento em trocar lâmpadas fluorescentes por tipo LED, já iniciado, ajudando a reduzir o consumo de energia elétrica da iluminação, um quesito analisado na metodologia do PROCEL-Edifica.

Por meio das análises dos resultados do sistema PROCEL-Edifica / PBE-Edifica, foram identificadas e sugeridas algumas medidas para a melhoria da eficiência energética, como continuidade da substituição das lâmpadas por modelos mais eficientes, alteração nos circuitos de iluminação, substituição de ares condicionados antigos por modelos mais eficientes, inclusão de elementos de sombreamento na torre e uso de películas polarizadas nos vidros. Com isso o objetivo específico de identificar oportunidades de melhorias tecnológicas e de materiais foi atendido. Foram levantados os custos para implementação de algumas medidas e os benefícios esperados. Desse modo, procurou-se abrir caminho para os gestores buscarem melhorias relacionadas a Eficiência Energética no TJ/SP-Pinheiros e no TJ/SP em geral, contribuindo para a implantação de objetivo estabelecido no Plano de Logística Sustentável.

As virtudes do sistema PROCEL-Edifica foram mostradas no estudo, como a facilidade de uso e replicação do método prescritivo deste sistema ou a boa base para análise dos dados coletados, entre outras. Lacunas foram encontradas, como dificuldades na coleta e falta de alguns dados, o que causou a necessidade do uso de aproximações.

\section{AGRADECIMENTOS}

Ao Tribunal de Justiça de São Paulo, pela colaboração e disponibilização de pessoal e informações durante a pesquisa. Ao Fundo de Apoio à Pesquisa - FAP/UNINOVE, pela bolsa integral oferecida ao aluno de mestrado Antonio Luiz Ferrador Filho. Agradecimento ao apoio do Conselho Nacional de Desenvolvimento Científico e Tecnológico - CNPq, por meio da Chamada CNPq N 11/2016 Produtividade em Desenvolvimento Tecnológico e Extensão Inovadora - DT. Processo 311357/2016-4

\section{REFERÊNCIAS}

Agarwal, Y., Balaji, B., Gupta, R., Lyles, J., Wei, M., \& Weng, T. (2010). Occupancy-driven energy management for smart building automation. In Proceedings of the 2nd ACM Workshop on Embedded Sensing Systems for Energy-Efficiency in Building (p. 1-6). ACM. Recuperado de http://dl.acm.org/citation.cfm?id=1878433. 
Altoé, L., Costa, J. M., Oliveira Filho, D., Martinez, F. J. R., Ferrarez, A. H., \& Viana, L. de A. (2017). Políticas públicas de incentivo à eficiência energética. Estudos Avançados, 31(89), 285-297. https://doi.org/10.1590/s0103-40142017.31890022

ARCOweb. (2005). Vidros: Produtos asseguram conforto aos ambientes - ARCOweb. Recuperado 16 de junho de 2016, de https://arcoweb.com.br/finestra/tecnologia/vidros-paraarquitetura-01-05-2005

Azens, A., \& Granqvist, C. (2003). Electrochromic smart windows: energy efficiency and device aspects. Journal of Solid State Electrochemistry, 7(2), 64-68. https://doi.org/10.1007/s10008002-0313-4

Banco Central do Brasil. Taxa Selic. Dados diários. ([s.d.]). Recuperado 21 de dezembro de 2017, de http://www.bcb.gov.br/htms/selic/selicdiarios.asp

Biderman, R., Macedo, L. S. V. de, Monzoni, M., \& Mazon, R. (2006). Guia de compras públicas sustentáveis: uso do poder de compra do governo para a promoção do desenvolvimento sustentável. Recuperado de http://bibliotecadigital.fgv.br/dspace/handle/10438/15417

Brasil. (2014). Instrução Normativa $N^{\circ} 2$, de 4 de Junho de 2014. Recuperado 16 de junho de 2016, de http://www.comprasgovernamentais.gov.br/paginas/instrucoesnormativas/instrucao-normativa-no-2-de-4-de-junho-de-2014

Brasil. (2016). Balanço Energético Nacional 2016 - ano base 2015. Empresa de Pesquisa Energética - EPE. Ministério de Minas e Energia - MME. Rio de Janeiro: EPE.

Brasil. (2017). EPE - Empresa de Pesquisa Energética (Brasil). Balanço Energético Nacional 2017: Relatório-síntese ano base 2016 / Empresa de Pesquisa Energética. - Rio de Janeiro : EPE.

Carlo, J. C. (2008). Desenvolvimento de metodologia de avaliação da eficiência energética do envoltório de edificações não-residenciais (Tese de doutorado). Universidade Federal de Santa Catarina - UFSC, Santa Catarina, SC, Brasil.

Carlo, J. C., \& Lamberts, R. (2010). Parâmetros e métodos adotados no regulamento de etiquetagem da eficiência energética de edifícios-parte 1: método prescritivo. Ambiente Construído, 10(2), 7-26.

Castleton, H. F., Stovin, V., Beck, S. B. M., \& Davison, J. B. (2010). Green roofs; building energy savings and the potential for retrofit. Energy and Buildings, 42(10), 1582-1591. https://doi.org/10.1016/j.enbuild.2010.05.004

Chen, C., Cook, D. J., \& Crandall, A. S. (2013). The user side of sustainability: Modeling behavior and energy usage in the home. Pervasive and Mobile Computing, 9(1), 161-175. https://doi.org/10.1016/j.pmcj.2012.10.004

Cheung, C. T., Mui, K. W., \& Wong, L. T. (2015). A hybrid simulation approach to predict cooling energy demand for public housing in Hong Kong. Building Simulation, 8(6), 603-611. https://doi.org/10.1007/s12273-015-0233-8

CNJ - Conselho Nacional de Justiça. (2015, março). Resolução n201-03-03-2015-presidência. Recuperado de http://www.cnj.jus.br/files/atos_administrativos/resoluo-n201-03-03-2015presidncia.pdf

Degani, C. M., \& Cardoso, F. F. (2002, outubro). A sustentabilidade ao longo do ciclo de vida de edifícios: a importância da etapa de projeto arquitetônico. NUTAU-2002 - Sustentabilidade, Arquitetura e Desenho Urbano. São Paulo, Brasil.

Didoné, E. L. (2009). A influência da luz natural na avaliação da eficiência energética de edifícios contemporâneos de escritórios em Florianópolis/SC (Dissertação de mestrado). Universidade Federal de Santa Catarina - UFSC, Santa Catarina, SC, Brasil.

Ferreira, C. C., \& Souza, R. V. (2009). Investigação sobre o potencial de economia de energia da iluminação natural. In X Encontro Nacional e VII Encontro Latino Americano de c o n fo r to 
$n$ o $a m b i$ b $n e c o n$ s $t r u$ í $d$ o (Vol. 10). Recuperado de https://www.researchgate.net/profile/Roberta_Souza3/publication/270282373_INVESTIGA O_SOBRE_O_POTENCIAL_DE_ECONOMIA_DE_ENERGIA_DA_ILUMINAO_NATURAL/links/54a 68ec20cf256bf8bb682ea.pdf

Ferreira, J. Z. (2014). Estudo comparativo entre lâmpadas fluorescentes tubulares T8 e tubulares de LED. Universidade Tecnológica Federal do Paraná, UTFPR.

Ferreira, M. A. M. A. (2009). A eficiência energética na reabilitação de edifícios (Dissertação de mestrado). Faculdade de Ciências e Tecnologia - Universidade Nova de Lisboa, Portugal - FCTUNL. Recuperado de http://run.unl.pt/handle/10362/2296

Ghisi, E., \& Lamberts, R. (1997). Avaliação das Condições de Iluminação Natural nas Salas de Aula da Universidade Federal de Santa Catarina. Recuperado de http://www.iar.unicamp.br/lab/luz/ld/Arquitetural/Ilumina\%E7\%E30\%20Natural/Pesquisa/a valiaca_das_condicoes_de_iluminacao_natural_em_salas_de_aula.pdf

Girod, B., Stucki, T., \& Woerter, M. (2017). How do policies for efficient energy use in the household sector induce energy-efficiency innovation? An evaluation of European countries. Energy Policy, 103(C), 223-237.

Goldstein, D. B., \& Eley, C. (2014). A classification of building energy performance indices. Energy Efficiency, 7(2), 353-375. https://doi.org/10.1007/s12053-013-9248-0

Gou, Z., Lau, S. S.-Y., \& Chen, F. (2012). Subjective and Objective Evaluation of the Thermal Environment in a Three-Star Green Office Building in China. Indoor and Built Environment, 21(3), 412-422. https://doi.org/10.1177/1420326X11419311

Hong, T., Chou, S., \& Bong, T. (2000). Building simulation: an overview of developments and information sources. Building and environment, 35(4), 347-361.

Huberman, N., \& Pearlmutter, D. (2008). A life-cycle energy analysis of building materials in the Negev desert. Energy and Buildings, 40(5), 837-848. https://doi.org/10.1016/j.enbuild.2007.06.002

INMETRO. (2013). Anexo geral V da Portaria INMETRO 50/2013. Recuperado de http://www.pbeedifica.com.br/sites/default/files/projetos/etiquetagem/anexos_rac/Anexo V.pdf

INMETRO. (2016, junho). Manual RTQ-C - Versão 4.

Issa, M. H., Rankin, J. H., \& Christian, A. J. (2010). Canadian practitioners' perception of research work investigating the cost premiums, long-term costs and health and productivity benefits of green buildings. Building and Environment, 45(7), 1698-1711. https://doi.org/10.1016/j.buildenv.2010.01.020

Jenkins, D., \& Muneer, T. (2003). Modelling light-pipe performances-a natural daylighting solution. Building and Environment, 38(7), 965-972. https://doi.org/http://dx.doi.org/10.1016/S0360-1323(03)00061-1

Juan, Y.-K., Gao, P., \& Wang, J. (2010). A hybrid decision support system for sustainable office building renovation and energy performance improvement. Energy and Buildings, 42(3), 290-297. https://doi.org/10.1016/j.enbuild.2009.09.006

Krarti, M. (2015). Evaluation of large scale building energy efficiency retrofit program in Kuwait. Renewable and Sustainable Energy Reviews, 50, 1069-1080. https://doi.org/10.1016/j.rser.2015.05.063

Kumbaroğlu, G., \& Madlener, R. (2012). Evaluation of economically optimal retrofit investment options for energy savings in buildings. Energy and Buildings, 49, 327-334. https://doi.org/10.1016/j.enbuild.2012.02.022 
Lamberts, R., Ghisi, E., Abreu, A. L. P. de, \& Carlo, J. C. (2005). Desempenho térmico de edificações. Curso: ECV 5161. LabEEE - Laboratório de Eficiência Energética em Edificações, UFSC Universidade Federal de Santa Catarina, Florianópolis, SC. Recuperado de http://www.ceap.br/material/MAT25022013164631.pdf

Leipziger, D. (2013). Comparing Building Energy Performance Measurement. Washington, DC: Institute for Market Transformation. Recuperado 7 de junho de 2016, de http://www.imt.org/uploads/resources/files/ComparingBuildingEnergyPerformanceMeasure mentFINAL.pdf

Li, R. Y. M. (2013). The usage of automation system in smart home to provide a sustainable indoor environment: a content analysis in Web 1.0. Li, Rita Yi Man (2013), The Usage of Automation System in Smart Home to Provide a Sustainable Indoor environment: A Content Analysis in Web, 1, 47-60.

Liu, S., Shukla, A., \& Zhang, Y. (2014). Investigations on the integration and acceptability of GSHP in the UK dwellings. Building and Environment, 82, 442-449. https://doi.org/10.1016/j.buildenv.2014.09.020

Lowe, R. (2000). Defining and meeting the carbon constraints of the 21st century. Building Research \& Information, 28(3), 159-175. https://doi.org/10.1080/096132100368939

Ma, Z., Cooper, P., Daly, D., \& Ledo, L. (2012). Existing building retrofits: Methodology and stateof-the-art. Energy and Buildings, 55, 889-902. https://doi.org/10.1016/j.enbuild.2012.08.018

McCormick, K., Neij, L., Mont, O., Ryan, C., Rodhe, H., \& Orsato, R. (2016). Advancing sustainable solutions: an interdisciplinary and collaborative research agenda. Journal of Cleaner Production, 123, 1-4. https://doi.org/10.1016/j.jclepro.2016.01.038

Melo, G. M., \& Rodrigues Júnior, W. (1998). Determinantes do investimento privado no Brasil: 1970-1995. Recuperado de http://repositorio.ipea.gov.br/handle/11058/2481

Memon, S. A. (2014). Phase change materials integrated in building walls: A state of the art review. Renewable and Sustainable Energy Reviews, 31, 870-906. https://doi.org/10.1016/j.rser.2013.12.042

Mo, K., Burt, L., Hao, B., Chen, J., Burr, A., \& Kemkar, S. (2010). Comparative Analysis of U.S. and China Building Energy Rating and Labeling Systems (2010 ACEEE Summer Study on Energy Efficiency in Buildings)

Moran, F., Blight, T., Natarajan, S., \& Shea, A. (2014). The use of Passive House Planning Package to reduce energy use and $\mathrm{CO}_{2}$ emissions in historic dwellings. Energy and Buildings, 75, 216227. https://doi.org/10.1016/j.enbuild.2013.12.043

Morris, P. (2007). What does green really cost. PREA quarterly, (Summer), 55-60.

Moulin Netto, J. (2014). Introdução para a versão brasileira. In: Kats, G. Tornando nosso ambiente construído mais sustentável: custos, benefícios e estratégias (VIII-X). São Paulo: Secovi-SP.

Neumann, C., \& Jacob, D. (2008). Guidelines for the evaluation of building performance. Building EQ, Project Report. Recuperado de http://buildingeq.org/fileadmin/user_upload/Results/report_wp3_080229_final.pdf

Ortiz-Rodríguez, Ó., Castells, F., \& Sonnemann, G. (2012). Environmental Impact of the Construction and Use of a House: Assessment of Building Materials and Electricity End-Uses in a Residential Area of the Province of Norte de Santander, Colombia. Ingeniería y Universidad, 16(1), 147-161.

Pereira, F. (2010). Determinação do Fator Solar em vidros e elementos de sombreamento para janelas (Relatório de Iniciação Científica - PIBIC/CNPq - BIP/UFSC 2009/2010). Florianópolis, SC, Brasil. 
Praznik, M., Butala, V., \& Senegačnik, M. Z. (2014). A simple method for evaluating the sustainable design of energy efficient family houses. Strojniški vestnik-Journal of Mechanical Engineering, 60(6), 425-436.

Roisin, B., Bodart, M., Deneyer, A., \& D'Herdt, P. (2008). Lighting energy savings in offices using different control systems and their real consumption. Energy and Buildings, 40(4), 514-523. https://doi.org/10.1016/j.enbuild.2007.04.006

Schnieders, J., \& Hermelink, A. (2006). CEPHEUS results: measurements and occupants' satisfaction provide evidence for Passive Houses being an option for sustainable building. Energy Policy, 34(2), 151-171. https://doi.org/10.1016/j.enpol.2004.08.049

Sedláková, A., Vilčeková, S., \& Burdová, E. K. (2015). Analysis of material solutions for design of construction details of foundation, wall and floor for energy and environmental impacts. Clean Technologies and Environmental Policy, 17(5), 1323-1332. https://doi.org/10.1007/s10098-015-0956-3

UNEP - United Nations Environment Programme (Org.). (2011). Towards a green economy: pathways to sustainable development and poverty eradication. Nairobi, Kenya: UNEP.

Venâncio, R., \& Pedrini, A. (2008). Influência de decisões arquitetônicas na eficiência energética de edificações do campus/UFRN. Encontro Nacional de Tecnologia do Ambiente Construído, 12. Recuperado de http://www.infohab.org.br/entac2014/2008/artigos/A1721.pdf

Yang, Z., \& Becerik-Gerber, B. (2014). The coupled effects of personalized occupancy profile based HVAC schedules and room reassignment on building energy use. Energy and Buildings, 78, 113-122. https://doi.org/10.1016/j.enbuild.2014.04.002

Yin, R. K. (2015). Estudo de Caso: Planejamento e método. Porto Alegre: Bookman.

Zheng, G., Jing, Y., Huang, H., Zhang, X., \& Gao, Y. (2009). Application of Life Cycle Assessment (LCA) and extenics theory for building energy conservation assessment. Energy, 34(11), 1870-1879. https://doi.org/10.1016/j.energy.2009.07.035 